\title{
A Comparative Study on Agricultural Production Efficiency Between China and Canada
}

\author{
Kong Tao \\ Department of Business, Guangdong AIB Polytechnic University, Guangzhou, China \\ Email address: \\ tkong@gdaib.edu.cn \\ To cite this article: \\ Kong Tao. A Comparative Study on Agricultural Production Efficiency Between China and Canada. International Journal of Agricultural \\ Economics. Vol. 4, No. 1, 2019, pp. 1-9. doi: 10.11648/j.ijae.20190401.11
}

Received: November 26, 2018; Accepted: December 19, 2018; Published: January 19, 2019

\begin{abstract}
Agricultural production efficiency is vital to the development level and quality of agricultural production. China is at a crucial stage of agricultural transformation, and it is of great significance to measure and calculate agricultural production efficiency by scientific methods. This paper conducts a case study of Chinese agriculture and Canadian agriculture, and measures and calculates the average values of gross agricultural output and the variations of agricultural production efficiency based on data envelopment analysis. According to the research results, firstly, Canadian agricultural production efficiency is much higher than that of China, holding a leading position in the world. Secondly, from 2005 to 2015 , the agricultural production efficiency of both China and Canada showed an overall rising trend, but there were obvious upward fluctuations in Chinese agricultural production efficiency. Thirdly, Chinese technical efficiency showed a rise and then a decline while the scale efficiency showed a decline at first and then a rise, and the overall efficiency showed a rise with fluctuations. At the same time, Canadian agriculture technical efficiency, scale efficiency and overall efficiency were all on the rise with fluctuations, and the efficiency values were significantly higher than those of China. Next, the Malmquist indices of both China and Canada appeared to change, but the rate of change of Canada was lower than that of China. Finally, based on Canadian agricultural production experience and combined with China's national conditions, this paper also puts forward the suggestions on improving Chinese agricultural production efficiency.
\end{abstract}

Keywords: Agricultural Production Efficiency, Data Envelopment Analysis, China, Canada, Suggestions

\section{Introduction}

Agriculture production is the basic activity for guaranteeing the survival and development of mankind. And the agricultural production efficiency is not only vital to the development level and quality of agricultural production, but the key to developing modern agriculture, achieving sustainable agricultural development, and upgrading the agricultural competitiveness in the international community [1-2]. In recent years, as the science and technology develops, domestic agricultural production efficiency is at increasingly higher level, but it should also be clearly recognized that, on the one hand, Chinese agricultural has a considerably weak foundation. The advancement of agricultural productivity is accompanied by resource shortage, severe pollution, low scale efficiency, and poor production conditions and other problems, and these problems have in turn restricted the improvement of agricultural production efficiency so that it is difficult for agricultural output to meet the domestic consumption demand for the agricultural products. On the other hand, Chinese agricultural development is facing the fierce competition and challenges in the international market, and production efficiency acts as the foundation of agricultural competition. Compared with developed countries, Chinese agricultural production efficiency is still at a relatively lower level [3]. Therefore, how to improve Chinese agricultural production efficiency has become the primary task for developing the modern agriculture and promoting the agricultural competitiveness.

The issue of agricultural production efficiency has also attracted extensive attention from the academic world. The scholars in the related fields have been focusing on the researches on the scientific evaluation of agricultural production efficiency [4]. In recent years, both domestic and foreign scholars have conducted a large number of researches on agricultural production efficiency of their respective 
country. Foreign scholars have done the studies on numerous aspects of agricultural production efficiency of their respect countries, including its methods, influencing factors and development directions (Goelli and Rao, 2005) [5]. Vincent (2004) adopted the data envelopment analysis (DEA) method to discuss Brazilian agricultural production efficiency, and it was shown that in Brazil, the pesticides and fertilizers had been fully utilized while other agricultural production factors failed to be fully utilized [6]. Krasachat (2000) based the study on the special national conditions of both developing countries and developed countries, analyzed the ways to improve the agricultural production efficiency respectively, and expounded the relationship between such improvements with grain production [7]. Additionally, domestic scholars mainly have focused on the coupling relationship between the grain production and agricultural production efficiency (Wang Fang et al., 2007) [8], regional differences between the provinces (Zhang Jing, 2017) [9], temporal and spatial changes (Zhou Liang et al., 2013) [10], and the applicable research methods (Xu Caihua, 2016) [11], and on this basis, some scholars also proposed the development directions of Chinese agricultural production efficiency (Liu Xuanze et al., 2016) [12]. For example, Wang Fang and others believed that rational allocation of agricultural resources could improve the coupling between the grain yield and agricultural production efficiency [8]; Zhang Jing found that there were significant differences in room for development of regional agricultural production efficiency in China from the perspective of food development, with great changes in agricultural production efficiency of different region [9]; Liu Xuanze and others considered that under the supply-side reform, Chinese grain production and agricultural production efficiency should be adjusted in terms of production and circulation in the context of supply-side reform, and furthermore, it was necessary to guarantee the good allocation of the existing agricultural resources, both of which were the directions of Chinese agricultural production efficiency development [12]; Wang Xuhui and Liu Yong (2008) used the DEA method to conduct the comprehensive evaluation of the agricultural production efficiency of 31 provinces in China, and they believed that the agricultural production efficiency of some major agricultural provinces had been at a low level from 2003 to 2005, and put forward the countermeasures for enhancing the agricultural production efficiency from the aspects including human resources, science and technology and the organization of agricultural production [13]; Ning Aifeng and Liu Youzhao (2013) employed the DEA method to make a quantitative analysis of the agricultural production efficiency of 11 prefecture-level cities in Zhejiang Province from 1990 to 2008, and concluded that the overall tendency of improvement of agricultural production efficiency in various prefecture-level cities was mainly brought by the technical progress [14].

Although there are many researches on the issue of agricultural production efficiency, this research literature mostly compares the agricultural production efficiency of the provinces in China whereas there are a relatively smaller number of research literatures involving the comparative analysis of agricultural production efficiency of China and other countries in the world. With China's accession to the WTO, the agricultural market has been increasingly open to the outside world. The development of domestic agriculture is not only constrained by the factors such as scarcity of domestic resources and environmental protection, but also faced with competition and impact from foreign agricultural products markets. Therefore, it is of both theoretically academic significance and reference value for promotion of Chinese agriculture production efficient to compare Chinese agricultural production efficiency with other countries, reveal the gaps, and to study on the causes and mechanisms of such gaps. At present, a small number of related researches are mainly qualitative researches. For example, Liu Yuhang et al. (2015) carried out the qualitative comparison and analysis of the differences in agricultural production efficiency between China and other agriculturally developed countries, such as the United States, Japan, and Australia, and tabled the policy recommendations on promoting the efficiency of agricultural production in China from the perspectives of agricultural inputs, technologies and others [15]. It is worth mentioning that Xing Xiaojun et al. (2010) adopted the Malmquist-DEA model to make a quantitative comparative analysis of agricultural production efficiency in China and seven other countries, and found that although Chinese agricultural production efficiency was higher than that of other developing countries, but far lower than that of the developed countries [16]. However, that article only studied the agricultural production efficiency at a whole, and failed to complete the subdivision of the agricultural production efficiency. In addition, such an article made the comparison between China and seven other countries at the same time, and to a certain extent, it also weakened the significance of targeted comparison between just two countries.

Both China and Canada are large agricultural countries with proximate land areas and a long history of agricultural culture. And they have established the cooperative relationship in many aspects of the agricultural sector. Moreover, Canada, which is a large North American country, is endowed with rich agricultural resources and favorable agricultural production environment, and also this country has the area of arable land ranking third in the world, with the incredibly high per capita arable land and the large volume of agricultural product export. The strong government support, intense environmental awareness of the public and the high-tech level of agriculture have contributed to the economic development of Canadian agriculture to a certain extent. In contrast, traditional Chinese agriculture restricts agricultural development, and the mountains and hills make up a large proportion of the land area, with a massive population. As a result, there are many problems in the agricultural production process. Drawing on the successful experience of Canadian agricultural production can make for improvement of Chinese grain production and agricultural product quality, maintenance of Chinese food 
security, promotion of the sustainable agricultural development, and enhancement of the agricultural competitiveness in international community. For that reason, this paper refers to numerous relevant literature, uses the DEA method to measure and calculate the agricultural production efficiency of Canada and China, and makes the comparative analysis of the differences in agricultural production efficiency between China and Canada. On this basis, according to the successful experience of Canadian agricultural production, and combined with the national conditions of Chinese agricultural development, this paper also provides the suggestions on decision-making for the improvement of China's agricultural production efficiency.

\section{Overview of Study Regions}

As one of the western economic powers, Canada's agriculture is still in a fundamental position in its national economy, with high-level agricultural productivity of labor and highly mechanized and technological agriculture. Its well-developed agriculture plays an important role in international agricultural products trade. At the same time, with China's accession to the WTO and the initiation of the strategic planning of China western development, China and Canada have continued to strengthen the cooperation in the fields of agricultural science and technology, mechanized services and agricultural products trade, and there are still remarkably broad prospects of cooperation. Therefore, the understanding of the natural and humanistic profiles and differences between the two countries becomes the premise and basis of drawing on the successful experience of Canadian agricultural production and making the appropriate policies according to the local situations in China.

Canada is located in the north of North America, with a land area of about 9.9846 million $\mathrm{km}^{2}$, and endowed with massive forest lands accounting for $44 \%$ of the national land area and ranking sixth in the world. Besides, the cultivated land area totals 68 million $\mathrm{hm}^{2}$; accounting for $8 \%$ of the national land area, and Canada's per capita arable land area is 18 times that of China. Moreover, Canadian agricultural products export ranks third in the world, and agricultural resources are also abundant (reported by DRCNET Statistical Database System, 2016). Canadian terrain is high in the west and low in the east, because of the mountainous located in the west and hilly located in the east. Due to the influence of the westerly wind, most of the areas are characterized by the temperate continental coniferous forest climate. The temperature in the east is slightly lower, with moderate climate in the south, mild and humid climate in the west and cold climate in the north. Canada is a typical agricultural country, and also attaches great importance to the research \& development and application of agricultural science and technology. And at the same time, Canadian agricultural productivity of labor is high, ranking on top of the world list, and considered as a highly developed agricultural country.

In contrast, China is located in the eastern part of Asia, with a land area of 9.6341 million $\mathrm{km}^{2}$ and an area of 1.831 billion $\mathrm{mu}\left(122\right.$ million $\left.\mathrm{hm}^{2}\right)$. However, the per capita arable land area of China is only about $1.5 \mathrm{mu}$, which is $1 / 18$ of the per capita arable land of Canada, and 1/3 of the global per capita arable land. China is one of the countries with the least per capita arable land (reported by DRCNET Statistical Database System, 2016). Additionally, Chinese terrain is high in the west and low in the east, dominated by mountainous and hilly. As regards the climate, China is characterized by the subtropical monsoon climate, and the annual precipitation is concentrated in the summer while it is cold and dry in the winter. China is a traditional agricultural country and one of the world's largest both producers and consumers of agricultural products. However, due to its huge population base and small per capita arable land, China is featured by relatively insufficient agricultural resources, small scale of agricultural production, and backward productivity [17].

\section{Research Methods}

\subsection{Data Envelopment Analysis}

The method of data envelopment analysis (DEA method) was proposed by Charnes which was a famous operations researcher, so as to evaluate the relative input-output efficiency of multiple decision-making units of the same type. Such a method applies the mathematical programming model to calculating and comparing the relative efficiency between the decision-making units [18]. When judging the evaluation unit, the DEA method can be used to better reflect the information and characteristics of the evaluation unit, with the advantages of avoiding the influence of subjective factors, simplifying the calculation and reducing the error. After the explicit proposal of the DEA method by Charnes, the method was applied by many scholars to the study of agricultural production efficiency [18]. For example, Haag et al. used the DEA method to make a systematical investigation into the agricultural production efficiency of 41 counties in a certain area of Texas, USA [19]; Chen Weiping used DEA method to analyze the spatial and temporal characteristics of Chinese agricultural production efficiency from 1990 to 2003 [20]; Zhou Duanming conducted the study of agricultural production efficiency in various regions of China from 1978 to 2005, discovering that there was a large imbalance between regions and technological progress had become the main driving force for the improvement of agricultural production efficiency through [21]. This paper draws on relevant researches, adopts the DEA method to measure and calculate the efficiency of agricultural production, and employs multiple input indicators including cultivated land, capital and labor, and also the output indicators including total agricultural output value and grain output. Relevant data is collected from DRCNET Statistical Database System, China's official websites and Canada's official websites.

\subsection{DEA-Malmquist Index Model}

In order to objectively measure the change in technical efficiency and also the internal relationship between technical 
efficiency change and agricultural production efficiency, this paper selects the geometric mean of Malmquist index from $t$ to $\mathrm{t}+1$, which was proposed by Caves et al. ${ }^{[18]}$. The formula is as follows:

$$
M_{0}\left(x_{t+1}, y_{t+1}, y_{t}\right)=\left[\frac{D_{0}^{t}\left(x_{t+1}, y_{t+1}\right)}{D_{0}^{t}\left(x_{t}, y_{t}\right)} \times \frac{D_{0}^{t+1}\left(x_{t+1}, y_{t+1}\right)}{D_{0}^{t+1}\left(x_{t}, y_{t}\right)}\right]^{1 / 2}
$$

Where $\left(x_{t}, y_{t}\right)$ and $\left(x_{t+1}, y_{t+1}\right)$ refer to the output and input of the $\mathrm{t}^{\text {th }}$ and $\mathrm{t}+1^{\text {th }}$ periods respectively, while $D_{0}^{t}\left(x_{t+1}, y_{t+1}\right)$ and $D_{0}^{t+1}\left(x_{t+1}, y_{t+1}\right)$ refer to input distance function and output distance function respectively obtained by comparing the production point with the frontier technology during the mixing period, and $D_{0}^{t}\left(x_{t}, y_{t}\right)$ and $D_{0}^{t+1}\left(x_{t}, y_{t}\right)$ refer to the input distance functions respectively obtained by comparing the production point with the frontier technology during the same period.

$$
\mathrm{M}\left(x_{t}, y_{t}, \quad x_{t+1}, \quad y_{t+1}\right)=\frac{S^{t}\left(x_{t}, y_{t}\right)}{S^{t}\left(x_{t+1}, y_{t+1}\right)} \times \frac{D^{t}\left(x_{t+1}, y_{t+1} / V R S\right)}{D^{t}\left(x_{t}, y_{t} / V R S\right)} \times\left[\frac{D^{t}\left(x_{t+1}, y_{t+1}\right)}{D^{t+1}\left(x_{t+1}, y_{t+1}\right)} \times \frac{D^{t}\left(x_{t}, y_{t}\right)}{D^{t+1}\left(x_{t}, y_{t}\right)}\right]
$$

Where $\frac{s^{t}\left(x_{t}, y_{t}\right)}{s^{t}\left(x_{t+1}, y_{t+1}\right)}$ refers to scale efficiency change, $\frac{D^{t}\left(x_{t+1}, y_{t+1} / V R S\right)}{D^{t}\left(x_{t}, y_{t} / V R S\right)}$ refers to pure technical efficiency change while $\left[\frac{D^{t}\left(x_{t+1}, y_{t+1}\right)}{D^{t+1}\left(x_{t+1}, y_{t+1}\right)} \times \frac{D^{t}\left(x_{t}, y_{t}\right)}{D^{t+1}\left(x_{t}, y_{t}\right)}\right]$ refers to technical efficiency change. When the scale efficiency change is more than 1 , it is suggested that the scale efficiency get improved; when the pure technical efficiency change is more than 1 , it is suggested that the agricultural management practices successfully improve the agricultural production efficiency; when the technical efficiency change is more than 1 , it is suggested that the technical progress is realized during the research; when the above indices is less than 1, it is shown that the efficiency drops off.

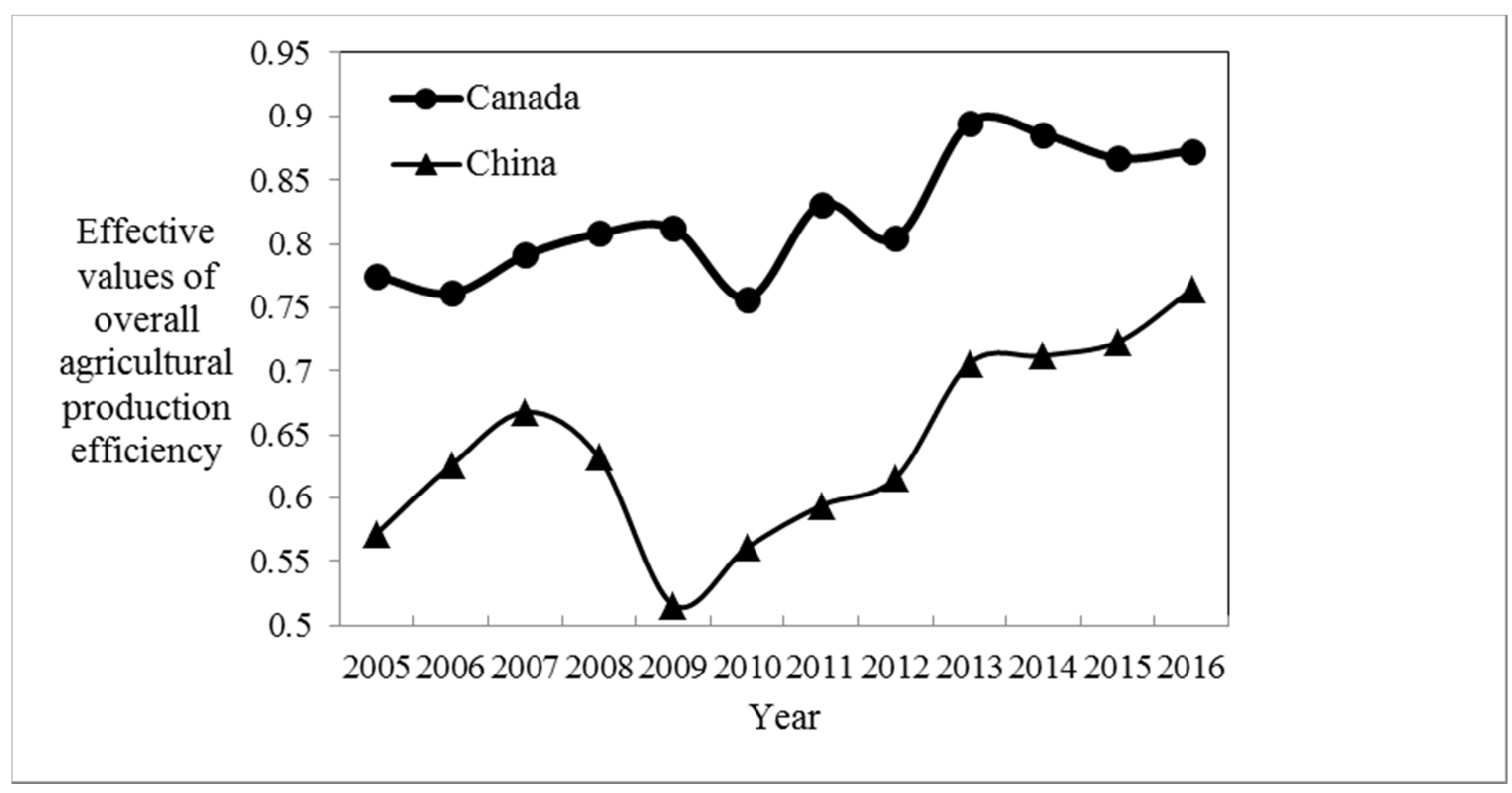

Figure 1. Changes in DEA effectiveness of Chinese and Canadian agricultural production.

\section{Data Analysis}

\subsection{Basic Evaluation of Agricultural Production Efficiency}

This paper uses the software DEAP2.1 to measure, calculate and analyze the agricultural production efficiency, technical efficiency and scale efficiency of China and Canada from 2005 to 2016 . It can be seen from Figure 1 that the DEA effectiveness of agricultural production in China has shown a slight increase since 2005, with the effective value varying from 0.57 to 0.67 . From 2007 to 2009, the effectiveness dropped off year by year, and finally the effective value dropped to 0.52 . And then the effective value showed a steady upward trend, and was close to 0.75 in 2016. Compared with China, the DEA effectiveness of Canadian agricultural production was significantly higher than that of China. During the research period, the effective value varied from 0.75 to 0.9 , but were at the leading edge of efficiency throughout the research years. This shows that Canadian agricultural input-output efficiency continues to be at a higher level, whereas Chinese agricultural production efficiency still needs to be further improved.

Table 1 presents the change in the mean of the overall efficiency, mean of technical efficiency, and mean of scale efficiency of agricultural production in China and Canada from 2005 to 2016. It can be seen from Table 1 that the 
average technical efficiency of China showed a two-stage change, including gradual increase from 2005 to 2009, and slow decline after 2009; the average scale efficiency declined from 2005 to 2007 at first and then rose up with fluctuations from 2008 to 2012, and finally dropped off with fluctuations from 2013 to 2016. In general, the mean of overall efficiency got enhanced slightly, but declined from 2005 to 2007, which can be inferred to be caused by the decline in the average scale efficiency. At the same time, from 2008 to 2016, the variation of overall efficiency was similar to that of technical efficiency and scale efficiency. It can be summarized that the change in the average value of the overall efficiency is caused by the combination of technical efficiency and scale efficiency. Since 2005 , the average value of overall efficiency has been varying between 0.623 and 0.743 . On the whole, the low Chinese agricultural technical efficiency indicates the failure in absolute establishment of the general environment for the popularization and application of science and technology in China's agricultural production, and also the relatively defective agricultural science and technology as well as applicable systems and policies. At the same time, the scale efficiency needs to be further improved. The aggregation of agricultural regions can act as the driving force for regional agricultural economy so as to finally promote the industrialization of agriculture, and to seek the production dividend for the farmers in the urbanized economies of scale.

In contrast, as a highly agriculturally developed country, Canada's agricultural production efficiency tops the list in the world, and its technical efficiency, scale efficiency, and overall efficiency are much higher than those of China. From 2005 to 2016, the average value of technical efficiency increased at first from 2005 to 2009 and then tended to be in a stable stat in the rest years. The average scale efficiency increased significantly from 2005 to 2009 , and tended to rise up and drop off slightly since then, but in general, the average scale efficiency got enhanced. In terms of overall efficiency, from 2005 to 2007 , the increase in the average value of overall efficiency was mainly affected by the average value of technical efficiency, but was jointly affected by the average value of technical efficiency and average value scale efficiency. As the seventh largest grain producer in the world, Canada takes the leading position in terms of grain production with strongly competitive advantages, because it considers the agricultural scientific research as an important link in food production. It has a competitive advantage. The Canadian government attaches great importance to funding for agricultural scientific research. In 2000-2001, Canadian agri-food research and development expenditures amounted to 1 billion Canadian dollars (one Canadian dollar is equivalent to about 4.90 yuan, 2018), of which more than 260 million Canadian dollars are provided by the Department of Agriculture and Agri-Food Canada. At the same time, Canadian scientists have conducted researches at a high level on agriculture. Through the development and introduction of innovative technologies, the long-term competitiveness of the agri-food sector has been enhanced. Canadian government launches the research center and network of experimental farms in each important agro-ecosystem. And each center has national key professional research directions that reflect the strength of the profession in the region. At the same time, Canada is vast and flat, with a large per capita arable land and highly mechanized agriculture. Moreover, there are specialized agricultural machinery and equipment suppliers in Canada, which can provide complete sets of production equipment for land preparation, irrigation and drainage, dry farming, the processing and storage of grain and special crops. These measures have promoted the improvement of its agricultural production efficiency.

Table 1. means of agricultural production efficiency of China and Canada in 2005-2016.

\begin{tabular}{|c|c|c|c|c|c|c|c|}
\hline China & & & & Canad: & & & \\
\hline year & $\begin{array}{l}\text { Mean of overall } \\
\text { efficiency }\end{array}$ & $\begin{array}{l}\text { Mean of technical } \\
\text { efficiency }\end{array}$ & $\begin{array}{l}\text { Mean of scale } \\
\text { efficiency }\end{array}$ & year & $\begin{array}{l}\text { Mean of overall } \\
\text { efficiency }\end{array}$ & $\begin{array}{l}\text { Mean of technical } \\
\text { efficiency }\end{array}$ & $\begin{array}{l}\text { Mean of scale } \\
\text { efficiency }\end{array}$ \\
\hline 2005 & 0.705 & 0.823 & 0.752 & 2005 & 0.778 & 0.887 & 0.801 \\
\hline 2006 & 0.688 & 0.857 & 0.718 & 2006 & 0.812 & 0.883 & 0.833 \\
\hline 2007 & 0.623 & 0.887 & 0.689 & 2007 & 0.815 & 0.878 & 0.878 \\
\hline 2008 & 0.668 & 0.892 & 0.713 & 2008 & 0.843 & 0.901 & 0.881 \\
\hline 2009 & 0.723 & 0.913 & 0.734 & 2009 & 0.887 & 0.923 & 0.901 \\
\hline 2010 & 0.688 & 0.901 & 0.711 & 2010 & 0.863 & 0.915 & 0.886 \\
\hline 2011 & 0.665 & 0.886 & 0.695 & 2011 & 0.861 & 0.909 & 0.889 \\
\hline 2012 & 0.714 & 0.883 & 0.751 & 2012 & 0.858 & 0.910 & 0.884 \\
\hline 2013 & 0.695 & 0.806 & 0.701 & 2013 & 0.877 & 0.931 & 0.891 \\
\hline 2014 & 0.721 & 0.823 & 0.771 & 2014 & 0.893 & 0.928 & 0.901 \\
\hline 2015 & 0.743 & 0.843 & 0.756 & 2015 & 0.879 & 0.906 & 0.909 \\
\hline 2016 & 0.712 & 0.827 & 0.738 & 2016 & 0.889 & 0.917 & 0.912 \\
\hline
\end{tabular}

\subsection{Analysis of Agricultural Production Efficiency of China and Canada}

According to the foregoing analysis, the Malmquist index can be used as the representation of change in the agricultural production efficiency, which can be further divided into the technological progress index and the technical efficiency index. And then the technical efficiency index can be further subdivided into the pure technical efficiency index and the scale efficiency index. The technical efficiency index can explain the utility of management methods, while the technical progress index can reflect the technical level of the 
industry.

As can be seen from Figure 2, the Malmquist index of China changed dramatically in 2005-2009, largely affected by the change in technical efficiency index. After 2009, the change in Malmquist index tended to be in a stable state. The pure technical efficiency index also played a certain role in the change in technical efficiency index, but less significant than that of scale efficiency index. Agriculture of scale is more suitable for large-scale mechanized production, thereby possibly leading to higher labor productivity. Judging from this point of view, there are significant differences between China and developed countries. Chinese agricultural labor productivity is $2 \%$ of the average productivity of developed countries, and $64 \%$ of the world's average productivity. In order to actively develop the operation of appropriate scale, the problem of property integration concerning the issue of land rights requires to be solved. In contrast, in addition to the intervention or supportive policies of government in agriculture, Canada sticks to the strict production management system. Consequently, even if dramatically changing, the technical efficiency has always been at a high level, and the Malmquist index shows a smaller rate of change than that of China.
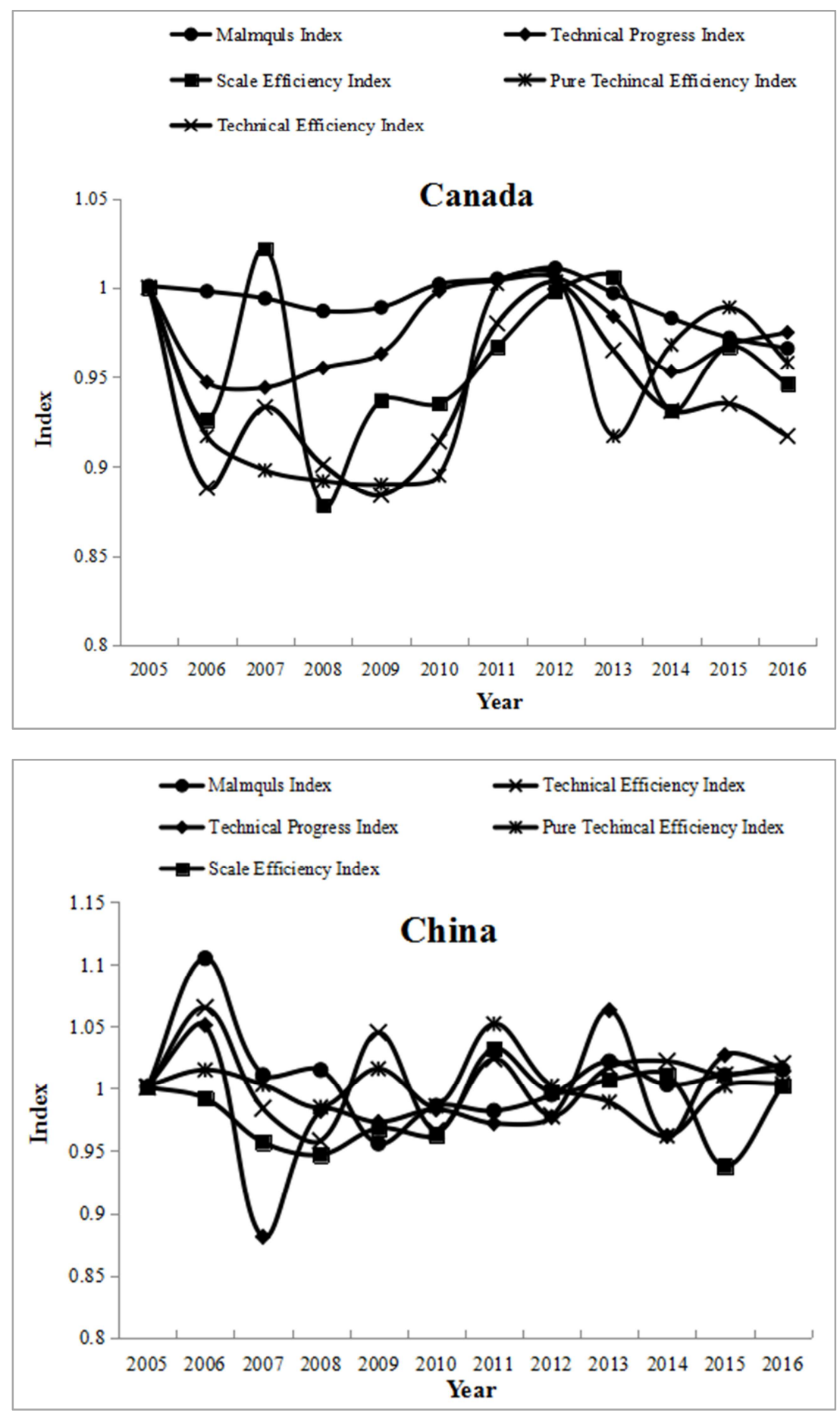

Figure 2. Malmquist index and its decomposition of China and Canada in 2005-2016. 
At the same time, Canada adopts strict and regular agricultural management system, and the introduction of relevant laws and regulations rather than subsidies or tariffs, is used to realize the control of import and export. As early as 1912, the Canadian government enacted the Grain Purchase and Quality Inspection Act, which provided that the protein content of exported wheat must reach $13.6 \%$, greatly improving the quality of its agricultural products. In addition, the federal government and provincial governments cooperate with each other with clear division of work. The federal government is mainly responsible for policy making, agricultural scientific research, and determination of agricultural product quality standards and regional development; the provincial governments act as the performer, mainly responsible for implementing relevant policies, agricultural technology applications and promotion, consultation service, etc. For example, the Canadian Wheat Board is in charge of realizing all aspects including production, transportation and sales of wheat, predicting market conditions, implementing price support policies, prepaying for grain to producers, and signing export contracts with foreign importers.

\section{Conclusion and Suggestions}

\subsection{Conclusion}

By means of DEA software, this paper measures and calculates the changes in the DEA effectiveness and average values of agricultural production efficiency in China and Canada from 2005 to 2016. At the same time, based on the Malmquist index, this paper also studies the changes in agricultural production efficiency, and obtains the following findings. Firstly, the DEA effectiveness of Chinese agricultural production showed a slight upward trend, while the DEA effectiveness of Canadian agricultural production was significantly higher than that of China, acting as a world leader. Secondly, Chinese technical efficiency rose at first and then decreased, while the scale efficiency decreased at first and then increased, and the overall efficiency showed an upward trend with fluctuations. However, Canadian technology efficiency, scale efficiency and overall efficiency showed an upward trend with fluctuations, and the values of each kind of efficiency were significantly higher than those of China. Thirdly, Chinese Malmquist index changed dramatically from 2005 to 2009, and remained steady after 2009, and the Canadian Malmquist index changed less sharply than that of China.

\subsection{Suggestions}

Agricultural production efficiency has always been the focus of attention in different countries. China is in an important stage of agricultural development transformation. At the same time, China has a large population base, so it is an important consumer of agricultural products. However, due to inadequate grain production capacity, China requires a large amount of imported agricultural products, and the only upgrade of Chinese agricultural production efficiency can ensure both the sustainable development of agriculture and food security. Canada is a large agricultural country with a high level of mechanization and technology, and there are busy trade of agricultural products between Canada and China. The cooperation between the two countries is promising. Therefore, this paper makes a comparative analysis of the general regional situations and agricultural production efficiency of China and Canada, aims at the problems existing in Chinese agricultural production currently, draws on the successful experience of Canadian agricultural production, and provides the following suggestions on further improving Chinese agricultural production efficiency, assuring the grain security, accomplishing sustainable agricultural development, and enhancing the agricultural competitiveness in the international community.

1). The large-scale and intensive operation along with technological application of mechanized and automated production is fundamental to improving agricultural production efficiency. Since the agricultural reform, Canada has introduced contiguous planting which means planting the same crop in one area, and applied the technology of mechanized and automated production. In this way, it is conducive to both production and management. In response to China's unique cultivation features of agricultural crops, it is feasible to learn from the foregoing planting model. For example, in the Sichuan Province known as the "Land of Abundance", especially in the Sichuan Basin, the superior geographic location provides natural conditions for rice planting. The government can learn from Canadian agricultural production mode, implement the removal of settlements that are conducive to agricultural production, carry out the contiguous planting of rice, and introduce the mechanized production technology so as to improve agricultural production efficiency and ensure food security.

$2)$. Efficient and perfect agricultural systems and social service act as the guarantees. In Canada, there are about 13 laws on agriculture, and the Canadian government puts the annual investment up to $\$ 7.3$ billion Canadian dollars into agriculture. In contrast, although China's agricultural system has been improved in recent years, such improvements are unsatisfactory. As far as Chinese agricultural development is concerned, the applicable laws and regulations for protecting and encouraging agricultural production can be continuously perfected. Besides, government departments at all levels should provide more social service for agricultural production and increase agricultural input so as to ensure the sustainable development of agriculture.

30. Pay much attention to the popularization and application of science and technology in agricultural production. It is suggested to strengthen the agricultural research funding. For example in Canada, the agricultural research funding is in a leading position in developed countries. In the meantime, it is necessary to promote the skills and quality of agricultural production personnel, so that they can act as not only production workers, but also the managers. Most of the agricultural production workers on Canadian 
farms have received the education in agricultural colleges or training for professional skills in agricultural production, and therefore, such production workers are highly competent in whether production technology or management skills. In addition, Canadian colleges and universities, research institutions, and the agricultural sector are considered as the bridges between farmers and the government. By establishing a connection mechanism between agricultural enterprises and institutions of higher education, advanced agricultural production technologies can be popularized and applied to agricultural production practices. Canada has established an immense agricultural cooperation network involving government agricultural departments at all levels, agricultural colleges and universities, and agricultural enterprises, contributing to the research \& development and application of agricultural science and technology. In contrast, China's agricultural research funding is insufficient, and there is also a lack of mechanisms of cooperation between agricultural enterprises and institutions of higher education as well as research institutions, leading to the low transformation rate of agricultural scientific and technological achievements.

4). Intensifying the publicity and reinforcing the farmers' awareness of environmental protection can play a role of driving force. Canadian well-developed agriculture and high agricultural production efficiency is not only because of the advanced technology and proper government management, but more importantly, due to the fact that the farmers are highly aware of environmental protection and willing to abide by the laws and regulations on environmental protection. China is a large developing country with a large population, and the exhaust gas and waste water cause by high-speed industrialization and urbanization has brought about the degeneration of the agro-ecological environment in China to a certain extent. Therefore, in order to protect the agro-ecological environment, it is essential to enhance the publicity of environmental protection and to continuously boost the farmers' awareness of environmental protection in agricultural production. The healthy agro-ecological environment is both the premise and basis for improving agricultural production efficiency and maintaining food security.

Funded by 2015 Outstanding Young Teacher Training Program for Higher Education of Guangdong Province: "Research on the Opportunity, Challenge and Path of State-owned Land-reclamation Enterprises' Shareholding Reform in Guangdong” (YQ2015201); 2016 "Outstanding Young Scholar" Scientific Research Project of Guangdong AIB Polytechnic College: "Research on Reform and Innovation of Guangdong Land-reclamation System"; 2017 Guangdong Regular Institutions of Higher Education Characteristic Innovation Project: "Exploration and Research on State-owned Land-reclamation Enterprises' Shareholding Reform in Guangdong".

\section{References}

[1] Peng Junjie. An Overview of Influence of Climate Change on Global Grain Output [J]. World Agriculture, 2017 (5): $19-24+64$.
[2] Liu Zifei, Wang Changhai. A Case Analysis of Organic Agricultural Production Efficiency in Yang County of Shaanixi Province Based on Three-Stage DEA Model [J]. China Population Resources and Environment, 2015, 25 (7): 105-112.

[3] Han Zhenguo. A Study on Adaptation Strategies and Practices of Chinese Agricultural Enterprises to Africa [D]. Beijing: China Agricultural University, 2017.

[4] Liu Yiwen, Hu Zongyi. An Analysis of Regional Differences in Carbon Emission Efficiency in China Based on the Three-Stage DEA Model and Super-Efficiency DEA Model [J] Journal of Shanxi University of Finance and Economics, 2015, 37 (2): 23-34.

[5] GOELLITJ, RAO DS. Total factor productivity growth in agriculture: a Malmquist Index analysis of 93 countries, 1980-2000 [J]. Agricultural Economics, 2005, 32 (1): 115-134.

[6] VICENTE J R. Economic efficiency of agricultural production in Brazil [J]. Revista De Economia E Sociologia Rural, 2004, 42 (2): 376-80.

[7] KRASACHAT W. Measurement of technical efficiency in Thai agricultural production [R]. The Chao Phraya Delta: Historical Development Dynamics and Challenges of Thailand's Rice Bowl, 2000.

[8] [8] Wang Fang, Ding Wenbin, Wang Yapeng. The Coupling Analysis of Farmers' Income Growth and Grain Security in Major Grain Producing Areas: An Empirical Analysis of Agricultural Production Efficiency in 18 Cities of Henan Province Based on DEA [J]. Journal of Northwest A\&F University (Social Science Edition), 2007 (5): 21-25.

[9] Zhang Jing. Analysis of Development and Regional Differences of Grain Production in China Based on Grain Development Index [J]. Jiangsu Agricultural Sciences, 2017, 45 (14): 257- 261.

[10] Zhou Liang, Xu Jiangang, Zhang Mingdou. Spatial-Temporal Variation of Agriculture Production Efficiency Under the Background of Grain Production Increase in the Huaihe River Basin [J]. Scientia Geographica Sinica, 2013, 33 (12): 1476-1483.

[11] Xu Caihua. A Study on Agricultural Production Efficiency of Shandong Province under the Background of Farmland Transfer [D]. Yangling: Northwest A\&F University, 2016.

[12] Liu Xuanze, Wang Shuguang, Zhang Kuan, et al. Analysis and Recommendations of the Production and Circulation of Grain in China at the Angle of Supply-Side Reform [J]. Geography and Geo-Information Science, 2016, 32 (6): 112-116.

[13] Wang Xuhui, Liu Yong. Overall Appraisal of Agricultural Production Efficiency in China Based on DEA Model [J]. Journal of Hebei University of Economics and Trade, 2008, 29 (1): 53- 59 .

[14] Ning Aifeng, Liu Youzhao. The Efficiency of Agricultural Grain Production under Urbanization [J]. Resources Science, 2013, 35 (6): 62-71.

[15] Liu Yuhang, Zhang Hongchen, Wang Zhidan, et al. Enlightenment and Reference for China from the Improvement of Agricultural Production Efficiency abroad-Taking the United States, Japan, Australia and Other Countries as an Example [J]. World Agriculture, 2015 (2): 60-63. 
[16] Xing Xiaojun, Sun Lijuan, Zhou Dequn. A Comparative Study on Agricultural Production Efficiency between China and Foreign Countries Based on the Malmquist-DEA model [J]. Journal of Business Economics, 2010 (9): 59-64.

[17] Wang Hefeng, Shi Yishao, Yin Changying. Research on Land Efficiency and Its Changes in the Shanghai Development Zone Based on the DEA model and Malmquist Productivity Index [J]. Geographical Research, 2014, 33 (9): 1636-1646.

[18] CHARNES A, COOPER W W, RHODES E. Measuring the efficiency of decision making units [J]. European Journal of Operational Research, 1978, 2 (6): 429-444.

[19] HAAG S, JASKA P, SEMPLEJ. Assessing the relative efficiency of agricultural production units in the Blackland Prairie, Texas [J]. Applied Economics, 1992, 24 (5): 559-565.

[20] Chen Weiping. Growth, Technical Progress and Efficiency Changes of China's Agricultural Productivity: 1990-2003 [J]. China Rural Survey, 2006 (1): 18-23.
[21] Zhou Duanming. Technical Progress, Technical Efficiency and Growth of Chinese Agricultural Productivity: An Empirical Analysis Based on DEA [J]. The Journal of Quantitative \& Technical Economics, 2009 (12): 70-82.

\section{Biography}

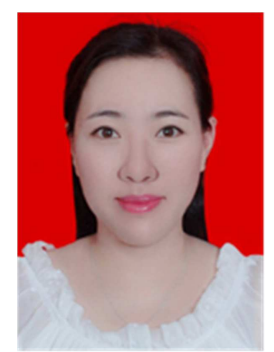

Kong Tao, female, born in Guangzhou of Guangdong, studied for a master's degree, is engaged in the research direction: enterprise management and economic development of Guangdong land-reclamation. 